\title{
Morphology of sporadic colorectal cancer with DNA replication errors
}

\author{
J R Jass, K-A Do, L A Simms, H Iino, C Wynter, S P Pillay, J Searle, G Radford-Smith, \\ J Young, B Leggett
} Department of
Pathology

J R Jass

Department of Surgery, University of Queensland C Wynter S P Pillay

Glaxo Conjoint Gastroenterology Laboratory

L A Simms

G Radford-Smith

J Young

B Leggett

Queensland Health Pathology Services, Royal Brisbane Hospital

J Searle

Queensland Institute of Medical Research and Centre for Statistics, University of Queensland, Queensland, Australia K-A Do

First Department of Surgery, Yamanashi Medical School, Japan $\mathrm{H}$ Iino

Correspondence to: Professor J R Jass, Department of Pathology, The University of Queensland Medical School, Herston, Queensland 4006, Australia.

Accepted for publication 18 December 1997

\begin{abstract}
Background-Up to $15 \%$ of colorectal cancers are characterised by DNA microsatellite instability (MIN), shown by the presence of DNA replication errors (RERs).
\end{abstract}

Aims-To identify pathological features that are discriminating for colorectal cancer (CRC) showing extensive MIN.

Subjects-A prospective series of 303 patients with CRC and no family history of either familial adenomatous polyposis or hereditary non-polyposis colorectal cancer.

Methods-DNA was extracted from fresh tissue samples and the presence of MIN was studied at nine loci that included TGF $\beta$ RII, IGFIIR, and BAX. The 61 cases showing RERs were compared with 63 RER negative cases with respect to a comprehensive set of clinical and pathological variables. Predictive utility of the variables was tested by decision tree analysis. Results-Twenty seven patients with CRC showed extensive RERs (three loci or more) (RER+) and 34 had limited RERs only ( $28=$ one locus; $6=$ two loci) $(\mathrm{RER}+l$ $-)$, yielding a bimodal distribution. RER+ cancers differed from RER- and RER+Icases. Tumour type (adenocarcinoma, mucinous carcinoma, and undifferentiated carcinoma) $(p=0.001)$, tumour infiltrating lymphocytes $(p=0.001)$, and anatomical site $(p=0.001)$ were the most significant of the discriminating variables. Algorithms developed by decision tree analysis allowed cases to be assigned to RER+ versus RER- and + $/-$ status with a global sensitivity of $81.5 \%$, specificity of $96 \%$, and overall accuracy of $93 \%$.

Conclusion-Pathological examination of CRC allows assignment of RER+ status; assignment is specific and relatively sensitive. Conversely RER- and RER+I- CRC are indistinguishable.

(Gut 1998;42:673-679)

Keywords: colon; rectum; colorectal cancer; DNA replication errors; morphology; microsatellite instability

Approximately $15 \%$ of sporadic large bowel cancers show DNA replication errors (RERs) or DNA microsatellite instability. ${ }^{2}$ Strand et $a l^{3}$ reported that mutations of DNA mismatch repair genes produced destabilisation of tracts of simple repetitive DNA in yeast and linked this observation to similar findings in both sporadic colorectal cancer and hereditary nonpolyposis colorectal cancer (HNPCC). ${ }^{4}$ This led to the cloning of human DNA mismatch repair genes, of which $\mathrm{hMSH} 2$ and hMLH1 were shown to be implicated in most cases of HNPCC..$^{5-8}$

Although sporadic RER positive colorectal cancers are viewed as non-familial counterparts of HNPCC, only a subset of sporadic RER positive cancers shows somatic mutation of hMSH2, hMLH1, or other DNA mismatch repair genes such as hPMS1 and hPMS $2 .{ }^{9}{ }^{10}$ This suggests that a proportion of RER positive CRC is not necessarily an exact sporadic counterpart of HNPCC. Either different DNA mismatch repair genes are implicated or the genes are switched off by altered methylation or the DNA microsatellite instability may be mild and epiphenomenal. For example, mild DNA microsatellite instability (one locus only) was not associated with certain features characterising HNPCC including poor tumour differentiation, location in proximal colon, and diploid DNA content. ${ }^{11}$ Conversely these features were seen when two or more loci were implicated. ${ }^{11}$ Further features of strongly RER positive sporadic cancers have been recognised including mucinous differentiation, ${ }^{12}$ a Crohn's like peritumoural lymphocytic reaction, ${ }^{13}{ }^{14}$ and tumour multiplicity. ${ }^{15} 16$

RER positive cancers, whether sporadic or associated with HNPCC, appear to show a molecular genetic spectrum that is distinct from common bowel cancer or cancer developing in familial adenomatous polyposis. APC, p53, and K-ras mutations occur with reduced frequency in HNPCC. ${ }^{17}$ In sporadic RER positive cancers there is a reduced frequency of p53 immunostaining ${ }^{13}{ }^{14}$ whereas mutations within small repeated sequences are found in three genes implicated in tumour progression: TGF $\beta$ RII ${ }^{18}$ IGFIIR, ${ }^{19}$ and BAX.$^{20}$ Mutations in TGF $\beta$ RII are also found in adenomas and carcinomas from patients with HNPCC..$^{17}$

The preceding data indicate that sporadic RER positive cancers differ in clinical, pathological, and molecular respects from sporadic RER negative cancers, but at least partly overlap with HNPCC. Conflicting data are explained by less stringent definitions of RER positivity. ${ }^{22}$ Given the fact that RER positive cancers will include some that are hereditary, may have a relatively favourable prognosis, ${ }^{11}$ and may conceivably respond differently to adjuvant therapy, ${ }^{23}$ it is desirable that they are recognised. The aim of this study was to assess the independent value of pathological criteria in the diagnosis of RER positive cancers 


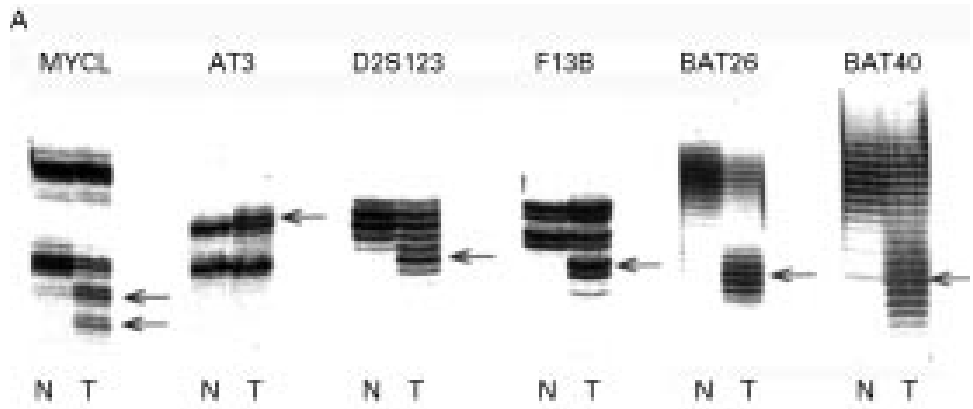

B

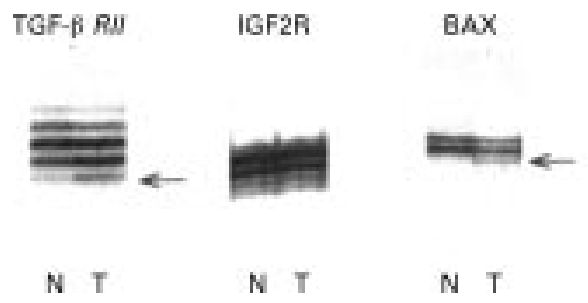

Figure 1 Example of cancer with extensive microsatellite instability implicating all six non-coding loci (row $A$ ) and TGFBRII and BAX in row B. The TGFBRI mutation is the most difficult to interpret, but confirmation by direct sequencing was achieved in seven cases including the one illustrated. ${ }^{25}$

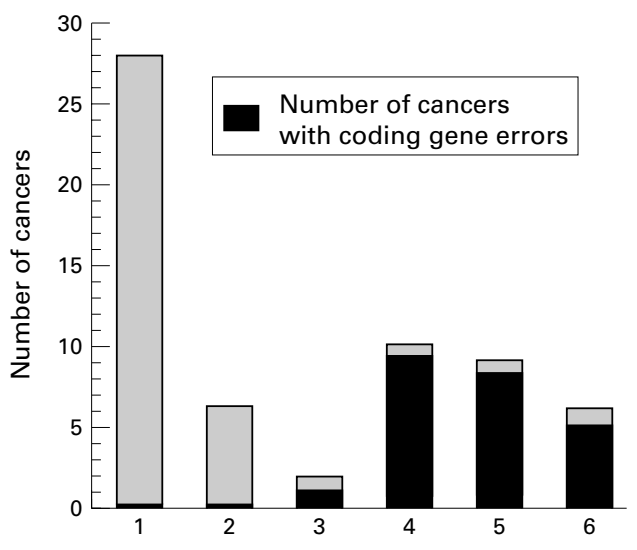

Figure 2 Number of microsatellite errors per cancer, showing cancers with errors in at least one of the coding genes: TGFBRII, IGFIIR, or BAX.

presenting in the absence of a family history of bowel cancer. Cribriform differentiation and tumour infiltrating lymphocytes were included in addition to the features reviewed earlier, as these were shown recently to be relatively sensitive for RER positive cancers. ${ }^{24}$ In this study RER positivity was classified as mild (up to two out of six loci) or extensive (three or more positive loci). Three additional loci within genes directly implicated in RER positive tumorigenesis-TGF $\beta$ RII, ${ }^{18}$ IGFIIR, ${ }^{19}$ and BAX $^{20}$ - were also studied.

\section{Materials and methods}

MATERIALS

The material was derived from a prospectively collected series of 303 fresh specimens of colorectal cancer obtained through the Royal Brisbane and Greenslopes Hospitals. The study was approved by the Royal Brisbane
Hospital Ethics Committee and all patients gave written informed consent.

DNA REPLICATION ERROR ASSAYS

DNA was extracted from the fresh specimens of cancer and from matching germline control samples (normal mucosa or, when not available, blood lymphocytes). In order to screen for RERs, these samples were amplified by polymerase chain reaction (PCR) at microsatellite loci MYCL, AT3, D2S123, F13B, ${ }^{25}$ BAT26 , and BAT- $40 .{ }^{26}$ PCR reactions were performed in a final volume of $20 \mu \mathrm{l}$, containing $100 \mathrm{ng}$ of genomic DNA, $20 \mathrm{pmol}$ of each oligonucleotide primer, $1.25 \mu \mathrm{M}$ of dATP, $10 \mu \mathrm{M}$ of dCTP, dTTP, and dGTP, $6 \mu \mathrm{Ci}\left[\alpha{ }^{35} \mathrm{~S}\right] \mathrm{dATP}$, and 1 unit of Taq polymerase (Boehringer Mannheim, Mannheim, Germany). Reaction conditions consisted of three minutes at $92^{\circ} \mathrm{C}$, followed by 31 cycles $\left(45\right.$ seconds at $94^{\circ} \mathrm{C}$, one and a half minutes at $55^{\circ} \mathrm{C}$, one and a half minutes at $72^{\circ} \mathrm{C}$ ), and a final extension for five minutes at $72^{\circ} \mathrm{C}$. PCR products were electrophoresed on denaturing $5 \%$ polyacrylamide (19:1) gels and visualised by autoradiography. Of the 303 cancers analysed for RERs, cases showing electrophoretic shifts at one or more loci were submitted for histopathological review $(n=61)$ together with a randomly selected group of RER negative cancers $(n=63)$. In addition, cancers with genetic alterations at one or more loci were analysed for the presence of TGFßRII (polyA), IGFIIR (polyG), and BAX mutations as previously described. ${ }^{19} 2027$

\section{HISTOPATHOLOGY}

Cases were reviewed by the first author without knowledge of the DNA RER status. Potential predictive variables for DNA microsatellite instability included: location (proximal colon up to and including splenic flexure, distal colon, and rectum); type of cancer (adenocarcinoma, mucinous carcinoma, undifferentiated carcinoma) ${ }^{28}$; differentiation (well, moderate, poor ${ }^{28}$; architecture (simple acini, cribriform structures, no lumina ${ }^{29}$; invasive margin (expanding, infiltrating $)^{30}$; peritumoural chronic inflammation, with or without Crohn's like lymphocytic nodules (present, absent) ${ }^{30}$; tumour infiltrating lymphocytes (present, absent) ${ }^{24}$; contiguous adenoma (present, absent); nodal status (involved, not involved); local spread (within wall, beyond wall); and modified Dukes' stage ${ }^{31}$ (A, B, C, and D for distant spread). For the purposes of this study, cancers were termed undifferentiated when they were composed primarily of large cells in solid sheets or broad trabeculae and had a well circumscribed margin. Unlike the series described by $\mathrm{Gibbs}^{32}$ these cases included a minor component with glandular spaces and were strictly a subset of poorly differentiated adenocarcinomas. A single signet ring cell carcinoma was classified as a poorly differentiated mucinous carcinoma.

STATISTICAL ANALYSIS

For univariate analyses, all key independent variables were investigated for possible associations with RER positive cancers by $\chi^{2}$ analyses 
Table 1 Distribution of variables in colorectal cancer by extent of DNA microsatellite instability

\begin{tabular}{|c|c|c|c|c|c|}
\hline Variable & $R E R-(n=63)$ & $R E R+/-(n=34)$ & $R E R+(n=27)$ & $\chi^{2}(-$ and $+/-v+)$ & $p$ Value \\
\hline Distant spread & $9(14.3)$ & $7(20.6)$ & $1(3.7)$ & 2.9 & 0.08 \\
\hline Proximal colon & $18(28.6)$ & $9(26.5)$ & $20(74.1)$ & 19.2 & 0.001 \\
\hline \multicolumn{6}{|l|}{ Type } \\
\hline Adenocarcinoma & $57(90.5)$ & $31(91.2)$ & $11(40.7)$ & \multirow{3}{*}{33.1} & \multirow{3}{*}{0.001} \\
\hline Mucinous carcinoma & $5(7.9)$ & $3(8.8)$ & $13(48.2)$ & & \\
\hline $\begin{array}{l}\text { Undifferentiated } \\
\text { carcinoma }\end{array}$ & $1(1.6)$ & $0(0)$ & $3(11.1)$ & & \\
\hline TIL & $0(0)$ & $1(2.9)$ & $9(33.3)$ & 29.7 & 0.001 \\
\hline $\begin{array}{l}\text { Peritumoural } \\
\text { lymphocytes }\end{array}$ & $9(14.3)$ & $10(29.4)$ & $8(29.6)$ & 1.3 & 0.26 \\
\hline Cribriform ${ }^{\star}$ & $13(20.6)$ & $9(26.5)$ & $10(37.0)$ & 2.3 & 0.13 \\
\hline \multicolumn{6}{|l|}{ Differentiated } \\
\hline Well & $11(17.5)$ & $9(26.5)$ & $5(18.5)$ & \multirow{3}{*}{7.69} & \multirow{3}{*}{0.02} \\
\hline Moderate & $45(71.4)$ & $21(61.8)$ & $13(48.2)$ & & \\
\hline Poor $\star$ & $7(11.1)$ & $4(11.8)$ & $9(33.3)$ & & \\
\hline Expanding & $48(76.2)$ & $27(79.4)$ & $25(92.6)$ & 3.2 & 0.08 \\
\hline
\end{tabular}

Values are expressed as number (\%).

*Undifferentiated carcinomas included in these categories.

TIL, tumour infiltrating lymphocytes.

$\chi^{2}$ for RER- versus RER+ for peritumoural lymphocytes $=3.2(\mathrm{p}=0.07)$.

of contingency tables (SAS PROC FREQ) (SAS Inst Inc. Cary, North Carolina, USA). All variables were subsequently included for multivariate analysis using classification tree methodology. The program CART (classification and regression trees) was used to construct a decision tree that can be used to predict a response variable (California Statistical Software Inc., Lafayette, California, USA, 1992). ${ }^{33}$ CART is a computer intensive nonparametric tool (in contrast to its parametric competitors such as Fisher's linear discriminant analysis or logistic regression) since it does not depend on any underlying distributional assumptions. ${ }^{34}$ CART allows for nonlinear relations between predictive factors and outcomes and for mixed data types (numerical and categorical), isolates outliers, and incorpo-

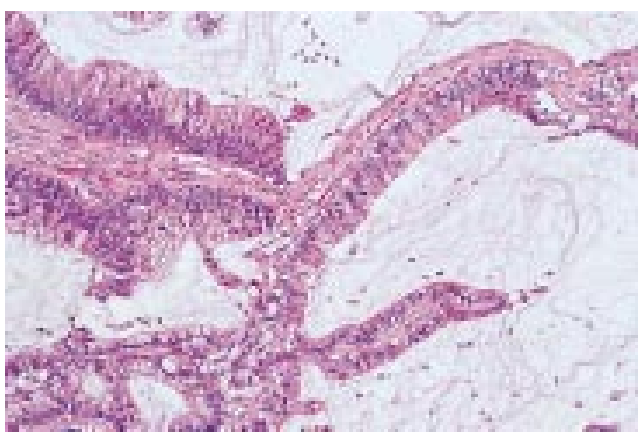

Figure $3 A$ well differentiated RER+ mucinous adenocarcinoma. Haematoxylin $\mathcal{E}$ eosin.

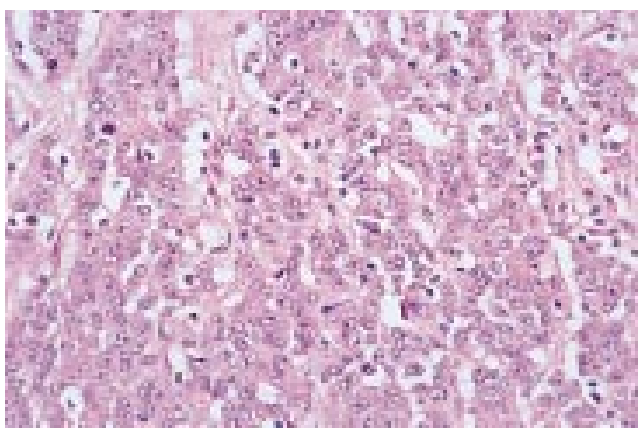

Figure 4 An undifferentiated RER+ carcinoma composed of solid aggregates of large cells. The tumour had a pushing margin (not shown). Foci of glandular differentiation were present (see fig 5). Haematoxylin $\mathcal{E}$ eosin. rates a pruning process using cross validation as an alternative to testing for unbiasedness with a second data set.

The tree is derived by recursive partitioning, beginning with the total sample population and all variables. At each step the program determines for each possible predictor variable a cutpoint which optimally splits the population into prespecified subgroups, and then selects the variable which performs best (according to some criterion based on impurities of the subgroups). If an observation has no data for this variable, the program uses the next most important variable (the surrogate) to sort that observation. It then takes the resulting subpopulations and repeats the process until

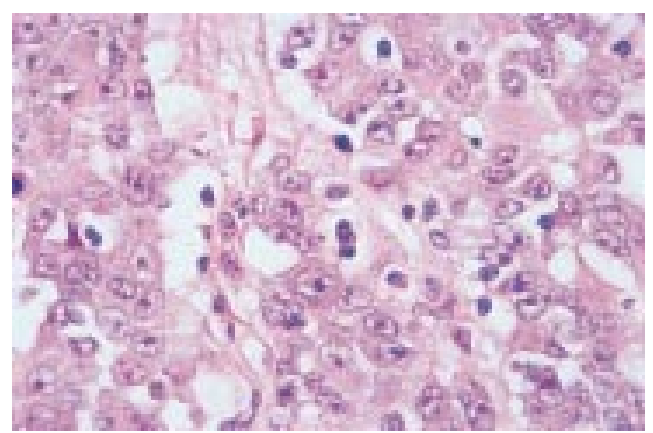

Figure 5. High power view of fig 4 showing occasional lumina indicative of poorly differentiated adenocarcinoma. Tumour infiltrating lymphocytes are peppered throughout and many are intraepithelial. Haematoxylin $\mathcal{E}$ eosin.

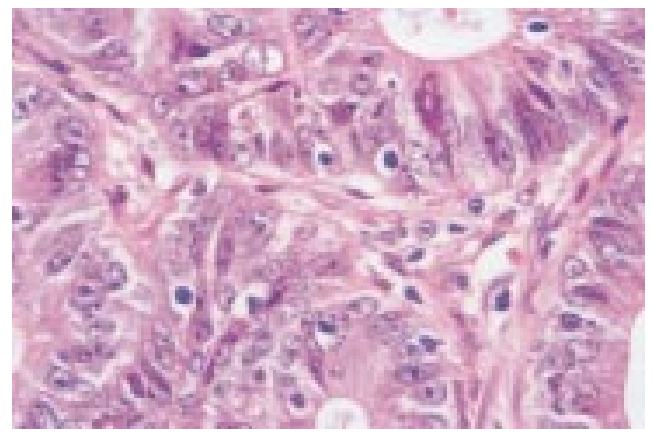

Figure 6 Moderately differentiated RER+ adenocarcinoma showing intraepithelial lymphocytes with retraction artefact. Distinction from mitoses and apoptotic bodies is straightforward. Haematoxylin $\mathcal{E}$ eosin. 


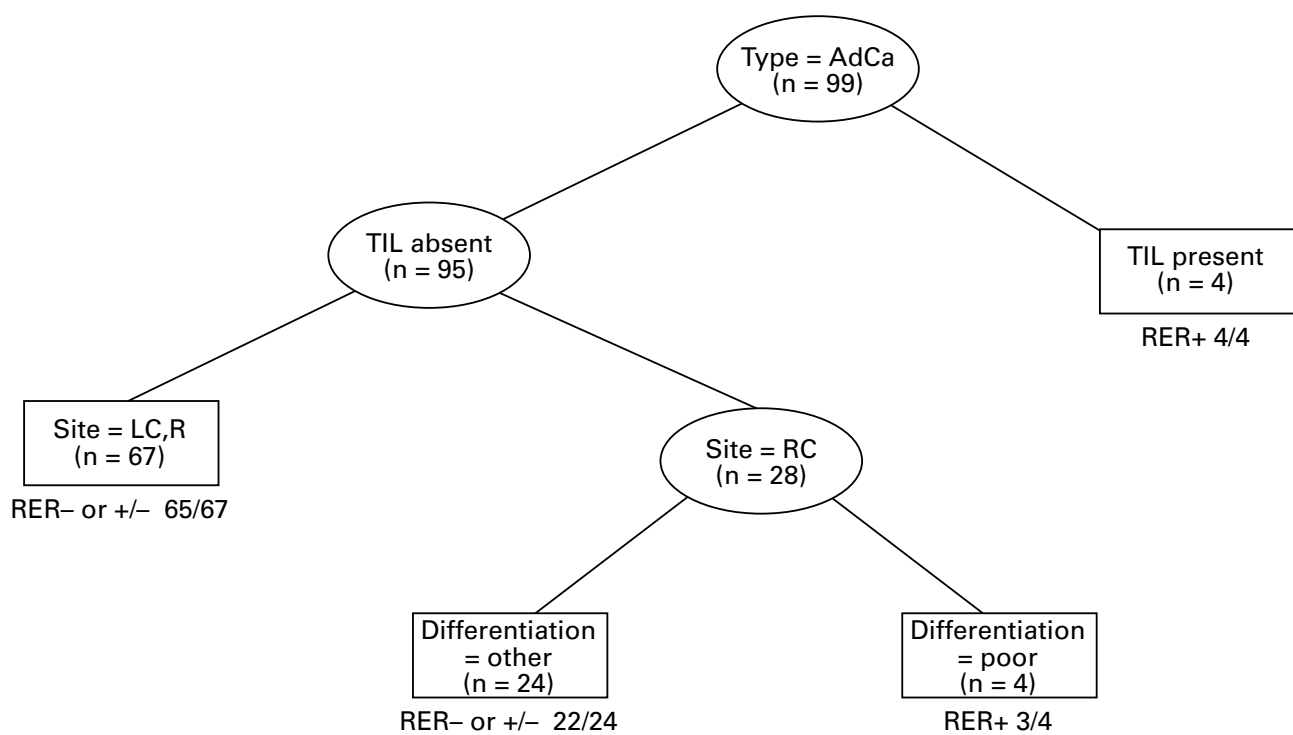

Figure 7 Decision tree analysis for adenocarcinomas. The ovals show the intermediate nodes and the boxes show the classifying groups and specify whether cancers are RER- or +/- versus RER+. Each box shows the sample size in the subgroup and the number that were correctly classified. Assessment of the predictive power of each variable is through the variable importance ranking and not the level shown on the tree. Relative rankings are: tumour infiltrating lymphocytes (TIL), 100; differentiation, 46; and site (RC), 13.

no further partitioning is warranted: either that a subpopulation contains only one class of the observed response variable or the subpopulation is too small to subdivide further. A "pruning" procedure then recombines subgroups if classification error is not significantly increased. During the partitioning process, the program keeps track of how well each predictor performs on each split and thus can evaluate its overall discriminating ability relative to the other factors in the analysis measured by variable importance rankings. The final result is a decision tree. Assessment of the predictive power of each variable is given by the variable importance ranking, rather than the level where it appears on the tree.

\section{Results}

The RER positive cancers included 34 with instability at two loci or less (RER+/-) and 27 with instability at three loci or more (RER+) (fig 1). Of the RER+/- cases only six showed instability at two loci and none had mutations of TGF $\beta$ RII, IGFIIR, or BAX. By contrast, all but four of the RER+ cancers showed at least one mutation implicating TGF $\beta$ RII, IGFIIR, or BAX (fig 2). The distribution of RER positive cancers (+ and $+/-$ ) was bimodal (fig 2 ).

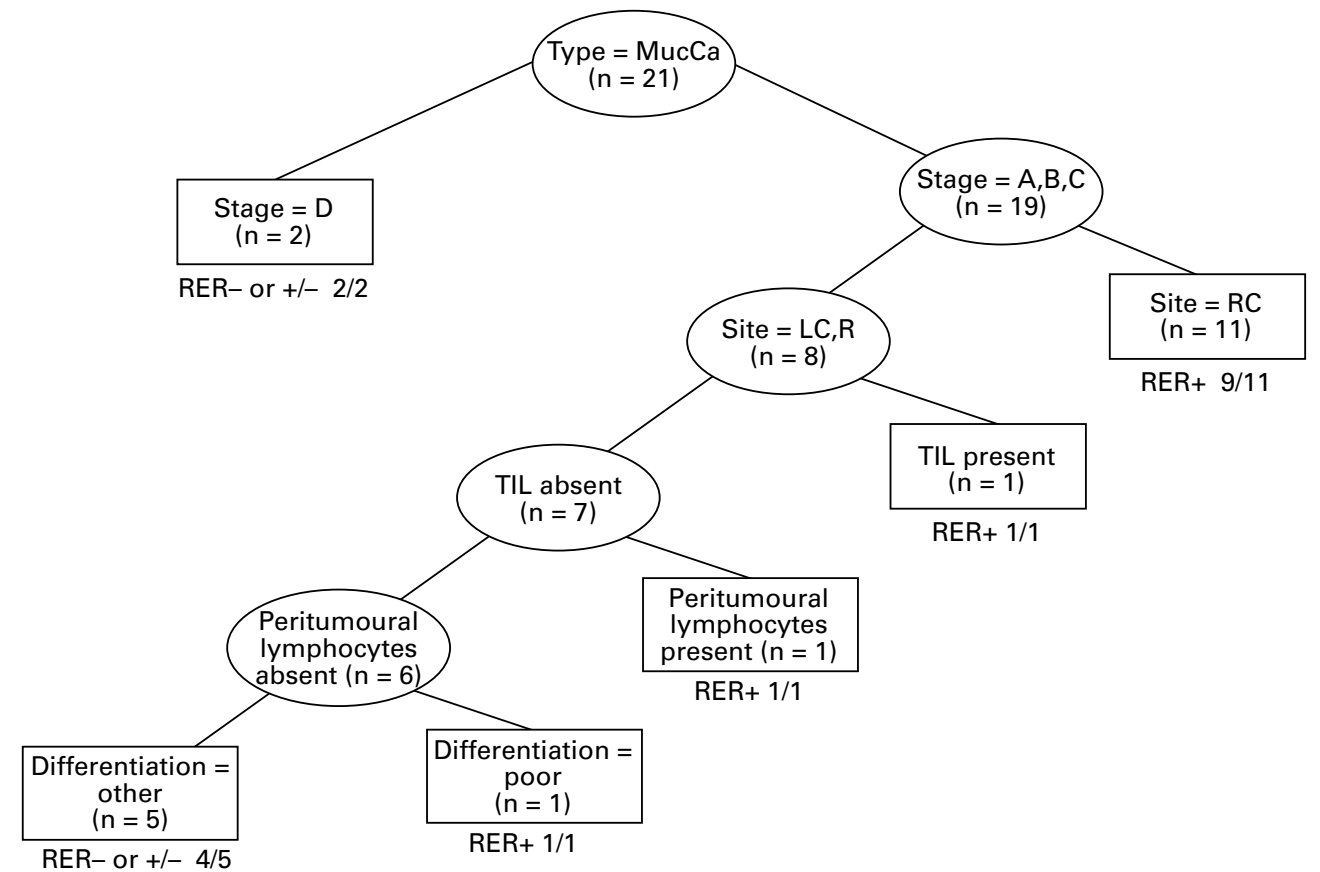

Figure 8 Decision tree analysis for mucinous carcinoma. Relative rankings are: stage D, 100; differentiation, 63; site (RC), 55; peritumoural lymphocytes, 45; and tumour infiltrating lymphocytes (TIL), 34. 
Variables showed a similar distribution in RER - and RER+/- cancers with the single exception of peritumoural lymphocytic infiltration, though the trend for this feature fell just short of significance $\left(\chi^{2}=3.2, p=0.07\right.$ ) (table 1). RER- and RER+/- cancers were therefore combined. No differences between RER+ versus RER- and RER+/- cancers were seen for nodal spread, direct spread, or contiguous adenomas. Differences were seen for the remaining variables, with type, tumour infiltrating lymphocytes, and location showing the largest $\chi^{2}$ values (table 1 ). Mucinous (fig 3 ) and undifferentiated cancer (fig 4) were over represented among RER+ cancers. Tumour infiltrating lymphocytes were most notable in undifferentiated cancers (fig 5), but were also observed in four RER+ adenocarcinomas (fig 6 ) and two RER+ mucinous carcinomas. The designation "undifferentiated" is not strictly correct, but serves to distinguish this large cell variant of poorly differentiated adenocarcinoma showing good circumscription and tumour infiltrating lymphocytes.

Decision tree analysis was performed for adenocarcinoma (fig 7) and mucinous carcinoma (fig 8). There were only four undifferentiated cancers and three of these were RER+. The decision tree analysis for adenocarcinoma yielded a test with an overall accuracy of $95 \%$ (overall correct assignment), a sensitivity of $64 \%$, and a specificity of $99 \%$. The decision tree analysis for mucinous carcinoma yielded a test with an overall accuracy of $85.7 \%$, a sensitivity of $92 \%$, and a specificity of $75 \%$. The global assignment accuracy for all types of carcinoma (adenocarcinoma, mucinous carcinoma, and undifferentiated carcinoma) was $93 \%$.

\section{Discussion}

In order to study morphological characteristics of RER positive colorectal cancer that might be diagnostically discriminating, a subset of RER+ cancers was recognised in which microsatellite instability was present in at least three of six loci. Only four of 27 cancers with microsatellite instability at three loci lacked a mutation of TGF $\beta$ IIR,${ }^{17}$ IGFIIR, $^{18}$ or BAX ${ }^{19}$ genes directly implicated in the tumorigenesis of RER positive cancers. Conversely, of the 34 cancers showing mild RER positivity (RER+/ -), all cases lacked mutation in TGF $\beta$ RII, IGFIIR, or BAX $(p<0.001)$. MYCL was the most frequently mutated locus among the $\mathrm{RER}+/-$ cases. Tetranucleotide (MYCL) instability may be less specific as a marker of extensive and significant RER positivity. Figure 2 indicates a bimodal distribution of RER+ and RER+/- cancers.

None of the variables was distributed differently between the RER- and RER+/- cancers, with the possible exception of peritumoural lymphocytes (table 1). RER- and RER+/cancers were therefore grouped together for the purposes of further analysis. Certain variables were distributed differently between RER+ and the remaining combined group (RERand $+/-$ ). The excess of poorly differentiated adenocarcinomas in the RER+ group included a distinct subset in which cells were grouped in irregular trabeculae or extensive sheets and the tumour was well circumscribed with a pushing margin. Three of the four cancers with this morphology were characterised by large numbers of tumour infiltrating lymphocytes, these cells being evident within the malignant epithelium as well as in the surrounding stromal elements (fig 5). Although these cancers were recognisably adenocarcinomas, they were predominantly undifferentiated. Gibbs $^{32}$ described a series of eight undifferentiated large bowel cancers which showed a pushing tumour margin. He stressed the importance of recognising this subgroup because of the excellent prognosis belying the lack of glandular differentiation. It is likely that some of these cancers were RER+. Furthermore, since two of the eight subjects in the study by Gibbs were under 50 years at the time of diagnosis (a woman aged 31 and a man aged 39) it is likely that these were HNPCC family members. Such undifferentiated or poorly differentiated cancers are known to be overexpressed in HNPCC $^{35}$ as well as among sporadic RER+ cancers. $^{11} 1336$

Mucinous carcinomas also occurred more frequently in the RER+ group. Indeed, they were the commonest subtype. The over expression of mucinous carcinoma has been recognised previously in both sporadic RER+ cancers $^{12} 1314$ and HNPCC. ${ }^{35}$ Since typing into adenocarcinoma, mucinous carcinoma, and undifferentiated carcinoma is fundamental to the classification of colorectal cancer and was the most significant discriminant, we commenced tree decision tree analysis with this variable. The additional useful discriminants for adenocarcinoma were the presence of tumour infiltrating lymphocytes, site, and differentiation. The decision tree for adenocarcinoma allowed RER+ cancers to be recognised with $99 \%$ sensitivity and $64 \%$ specificity. There were only four undifferentiated cancers and further subdivision of this group was inappropriate. Three were RER+. Interestingly, the single RER- case lacked tumour infiltrating lymphocytes.

The large mucinous group required a decision tree analysis of greater complexity, but this yielded a test that was $75 \%$ sensitive and $92 \%$ specific. Although tumoural lymphocytes have been noted to be prominent in subsets of $\mathrm{HNPCC}^{34}$ and in sporadic RER+ cancers, ${ }^{13}{ }^{14}$ this study has shown a more selective association with tumour infiltrating lymphocytes (figs 5 and 6), an observation that should be credited to Krishna et al. ${ }^{24}$ There is a negative correlation between peritumoural lymphocytic infiltration and notable mucin production. ${ }^{37}$ As a high proportion of RER+ cancers are mucinous (sporadic and HNPCC associated) this fact must confound any association with peritumoural lymphocytic infiltration. Nevertheless, tumour infiltrating lymphocytes were conspicuous in two (15\%) of 13 RER+ mucinous carcinomas. Of the 27 RER+ cancers, nine $(33 \%)$ showed tumour infiltrating lymphocytes. 
The biological significance of tumour infiltrating lymphocytes is unclear. It has been suggested that RER+ cancers would be prime targets for cytotoxic $T$ cells because they must express neoantigens translated from multiply mutated genes. At the same time, RER+ cancers will be under severe selective pressure to escape $\mathrm{T}$ cell cytotoxicity through loss of HLA expression and this has been shown to be the case. ${ }^{38}$ Tumour infiltrating lymphocytes have low proliferative capacity, even when exposed to interleukin $2 .^{3940}$ However when cultured with interleukin 2 , these cells show non-MHC restricted cytotoxicity to autologous tumour cell targets. ${ }^{41}$ Although such cytotoxicity is occurring within an artificial environment, it is conceivable that loss of HLA expression may not render RER+ cancers immune from $\mathrm{T}$ cell destruction. Indeed apoptotic bodies may be numerous in RER+ cancers (unpublished observation), requiring careful distinction from tumour infiltrating lymphocytes. The apoptotic effect could be triggered by the lymphocytes, but mediated by $\mathrm{BAX}^{20}$ Among RER+ cancers, tumour infiltrating lymphocytes were as frequent in specimens with a BAX mutation (40\%) as those without $(31 \%)$. We are currently examining the possibility that apoptosis may be reduced in specimens with BAX mutations, despite the presence of tumour infiltrating lymphocytes.

When RER positivity was diagnosed using stringent molecular criteria, morphological features combined with site and distant spread were found to be specific and sensitive for the recognition of this subgroup of CRC. Using the algorithms, $93 \%$ of cancers were correctly assigned to the RER+ versus RER- and +/groups (global accuracy), $81.5 \%$ of RER+ cancers were correctly assigned (global sensitivity), and $96 \%$ of RER- and +/- were correctly assigned (global specificity). Recognition of RER+ cancers is of practical value because of the association with HNPCC. In the present series, none of the RER+ cancers was from an individual with a family history of HNPCC and the advanced age of these subjects (mean 71.1 years) makes it likely that most, if not all, were sporadic cases. Twenty seven of 303 cancers $(8.9 \%)$ were RER+. Recognition of sporadic RER+ CRC is of importance because of the different prognosis, ${ }^{11}$ possible increased likelihood of multiplicity, ${ }^{15}{ }^{16}$ different profile of molecular tumorigenesis, and possibly different response to chemotherapy. ${ }^{23}$ In this study, RER+ cancers were less likely to be associated with distant spread ( $1 / 27$ cases) but the difference fell short of significance $(\mathrm{p}=0.08)$. Multiple colorectal cancer occurred in $11.0 \%(3 / 27)$ of RER+ but only $2.0 \%$ (2/97) of RER- and $+/-$ cases in the present study (Fisher's exact test, $\mathrm{p}=0.046$ ).

We conclude that pathological examination of colorectal cancer allows identification of cancers showing extensive DNA microsatellite instability (RER+) and that assignment is both specific and sensitive. Similar algorithms would assist in the morphological identification of CRC in HNPCC, although the right sided predilection may be more pronounced in the case of sporadic RER+ cancers. Weakly RER positive $(\mathrm{RER}+/-)$ cancers are indistinguishable from RER negative CRC. Weak RER positivity may be epiphenomenal and lacking in clinical significance or biological significance apart from an association with peritumoural lymphocytic infiltration. Although this study used decision tree modelling with multiple cross validation steps (using subsets of the data), the relatively small sample size and the subjectivity of some of the variables may limit the general applicability of the algorithms. On the other hand, the possibility of studying two or more cancers from members of a suspected HNPCC family would enhance diagnostic recognition considerably. It is unlikely that RER testing will be routinely available for the foreseeable future and DNA obtained from old formalin fixed material often fails to amplify adequately. Histopathological and clinical features that distinguish RER+ cancers are therefore likely to assume diagnostic importance and should be recorded as a routine.

We thank Mrs B Mason for typing the manuscript and Mrs L Reid and $\mathrm{Mr} \mathrm{C}$ Winterford for photographic assistance. CW and SPP thank the Sir Edward Dunlop Medical Research Foundation for financial assistance. During this study LAS was supported by the Queensland Cancer Fund.

1 Thibodeau SN, Bren G, Schaid D. Microsatellite instability in cancer of the proximal colon. Science 1993;260:816-19.

2 Ionov Y, Peinado MA, Malkhosyan S, et al. Ubiquitous somatic mutations in simple repeated sequences reveal a new mechanism for colonic carcinogenesis. Nature 1993; 363:558-61.

3 Strand M, Prolla TA, Liskay RM, et al. Destabilisation of tracts of simple repetitive DNA in yeast by mutation affecting DNA mismatch repair. Nature 1993;365:274-6.

4 Aaltonen LA, Peltomäki PS, Leach FS, et al. Clues to the pathogenesis of familial colorectal cancer. Science 1993; 60:812-16.

5 Fishel R, Lescoe MK, Rao MRS, et al. The human mutator gene homolog MSH2 and its association with hereditary nonpolyposis colon cancer. Cell 1993;75:1027-38.

6 Leach FS, Nicolaides NC, Papadopoulos N, et al. Mutations of a mutS homolog in hereditary nonpolyposis colorectal cancer. Cell 1993;75:1215-25.

7 Bronner CE, Baker SM, Morrison PT, et al. Mutation in the DNA mismatch repair gene homologue hMLH1 is associated with hereditary non-polyposis colon cancer. Nature 1994;368:258-61.

8 Papadopoulos N, Nicolaides NC, Wei Y-F, et al. Mutation of a mutL homolog in hereditary colon cancer. Science 1994; 263:1625-9.

9 Liu B, Nicolaides NC, Markowitz S, et al. Mismatch repair gene defects in sporadic colorectal cancers with microsatellite instability. Nat Genet 1995;9:48-55.

10 Børresen A-L, Lothe RA, Meling GI, et al. Somatic mutations in the hMSH2 gene in microsatellite unstable colorectal carcinomas. Hum Mol Genet 1995;4:2065-72.

1 Lothe RA, Peltomäki P, Meling GI, et al. Genomic instability in colorectal cancer: relationship to clinicopathological variables and family history. Cancer Res 1993;53:5849-52.

12 Messerini L, Vitelli F, De Vitis LR, et al. Microsatellite instability in sporadic mucinous colorectal carcinomas: relationship to clinico-pathological variables. If Pathol 1997;182:380-4.

$13 \mathrm{Kim} \mathrm{H}$, Jen J, Vogelstein B, et al. Clinical and pathological characteristics of sporadic colorectal carcinomas with Pathol 1994;145:148-56.

14 Bocker T, Schlegel J, Kullmann F, et al. Genomic instability in colorectal carcinomas: comparison of different evaluation methods and their biological significance. I Pathol 1996;179:15-19.

15 Horii A, Han HJ, Shimada M, et al. Frequent replication errors at microsatellite loci in tumors of patients with multiple primary cancers. Cancer Res 1994;54:3373-5.

16 Cawkwell L, Li D, Lewis FA, Martin I, et al. Microsatellite instability in colorectal cancer: improved assessment using luorescent polymerase chain reaction. Gastroenterology 1995;109:465-71.

17 Konishi M, Kikuchi-Yanoshita R, Tanaka K, et al. Molecular nature of colon tumors in hereditary nonpolyposis colon cancer, familial polyposis, and sporadic colon cancer. Gastroenterology 1996;111:307-17.

18 Markowitz S, Wang J, Myeroff L, et al. Inactivation of the type II TGF- $\beta$ receptor in colon cancer cells with microsatellite instability. Science 1995;268:1336-8. 
19 Souza RF, Appel R, Yin J, et al. The insulin-like growth factor II receptor gene is a target of microsatellite instability in
human gastrointestinal tumours. Nat Genet 1996;14:2557 .

20 Rampino N, Yamamoto H, Ionov Y, et al. Somatic frameshift mutations in the BAX gene in colon cancers of the microsatellite mutator phenotype. Science 1997;275: 967-9.

21 Akiyama Y, Iwanaga R, Saitoh K, et al. Transforming growth factor $\beta$ type II receptor gene mutations in adenomas from hereditary nonpolyposis colorectal cancer. Gastroenterology 1997;112:33-9.

22 Ilyas $M$, Tomlinson IPM, Novelli MR, et al. Clinicopathological features and p53 expression in left-sided sporadic colorectal cancers with and without microsatellite instability. F Pathol 1996;179:370-5.

23 Carethers JM, Hawn MT, Chauhan DP, et al. Competency in mismatch repair prohibits clonal expansion of cancer cells treated with $\mathrm{N}$-methyl-N'-nitro-N-nitrosoguanidine. $\mathcal{F}$ Clin Invest 1996;98:199-206.

24 Krishna M, Burgart LJ, French AJ, et al. Histopathologic features associated with microsatellite instability in colorectal carcinomas [abstract]. Gastroenterology 1996;110: A546.

25 Souza RF, Lei J, Yin J, et al. A transforming growth factor- $\beta 1$ receptor type II mutation occurs in ulcerative colitis-associated and sporadic colorectal neoplasms, but not in gastric or esophageal carcinomas. Gastroenterology 1997;112:40-5.

26 Parsons R, Myeroff LL, Liu B, et al. Microsatellite instability and mutations of the transforming growth factor $\beta$ type II receptor

27 Myeroff LL, Parsons R, Kim S-J, et al. A transforming growth factor $\beta$ receptor type II gene mutation common in colon and gastric but rare in endometrial cancers. Cancer Res 1995;55:5545-7.

28 Jass JR, Sobin LH. Histological typing of intestinal tumours. WHO International Classification of Tumours. Berlin: Springer-Verlag, 1989.
29 Jass JR, Atkin WS, Cuzick J, et al. The grading of rectal cancer: historical perspectives and a multivariate analysis of

30 Jass JR, Ajioka Y, Allen JP, et al. Assessment of invasive growth pattern and lymphocytic infiltration in colorectal cancer. Histopathology 1996;28:543-8.

31 Dukes CE. The classification of cancer of the rectum. $f$ Pathol Bacteriol 1932;35:323-32.

32 Gibbs NM. Undifferentiated carcinoma of the large intestine. Histopathology 1977;1:77-84.

33 Breiman L, Friedman JH, Olshen RA, et al. Classification and regression trees. Belmont, California: Wadsworth International Group, 1984

34 Schmoor C, Ulm K, Schumacher M. Comparison of the Cox model and the regression tree procedure in analysing a randomized clinical trial. Stat Med 1993;12:2351-66.

35 Jass JR, Smyrk TC, Stewart SM, et al. Pathology of hereditary non-polyposis colorectal cancer. Anticancer Res 1994; 14:1631-4.

36 Rüschoff J, Dietmaier W, Lüttges J, et al. Poorly differentiated colonic adenocarcinoma, medullary type. Clinical,
phenotypic, and molecular characteristics. Am f Pathol phenotypic, and m.

37 Sasaki P, Atkin WS, Jass JR. Mucinous carcinoma of the rectum. Histopathology 1987;11:259-72.

38 Branch P, Bicknell DC, Rowan A, et al. Immune surveillance in colorectal carcinoma. Nat Genet 1995;9:231-2.

39 Bland PW, Britton DC, Richens ER, et al. Peripheral, mucosal and tumour-infiltrating components of cellular immunity in cancer of the large bowel. Gut 1981;22:744-51.

40 Miescher S, Whiteside TL, Carrel S, et al. Functional properties of tumour-infiltrating and blood lymphocytes in patients with solid tumours: effects of tumour cells and their supernatants on proliferative responses of lymphocytes. F Immunol 1986;136:1899-907.

41 Yoo YK, Heo DS, Hata K, et al. Tumour infiltrating lymphocytes from human colon carcinomas. Functional and phenotypic characteristics after long-term culture in and phenotypic characteristics after long-term culture in
recombinant interleukin 2. Gastroenterology 1990;98:25968 . 